\title{
LOS GRUPOS DE SOCIEDADES. UN ANÁLISIS PENDIENTE ACERCA DE UNA REGULACIÓN SISTEMÁTICA EN LA LEGISLACIÓN ESPAÑOLA
}

\section{Corporate groups. An outgoing analysis about a systematic regulation lope in the Spanish legislation}

Nayiber Febles Pozo* Universidad de Girona Girona, España

RESUMEN: Este trabajo realiza un análisis crítico acerca del grupo de sociedades en el ordenamiento jurídico español, desde el punto de vista doctrinal y jurisprudencial. El autor enfatiza la dispersión jurídica al respecto, así como el necesario reconocimiento explícito de los grupos de sociedades en la legislación española. El autor también discurre acerca del concepto de grupos de sociedades en otros ordenamientos jurídicos, tales como el portugués y el brasileño, con especial atención al grupo jerárquico o grupo por subordinación.

PALABRAS CLAVE: grupos de sociedades, dirección unitaria, control, derecho español

Doctorando Universidad de Girona, Girona, España. Correo electrónico: <feblespozo@ gmail.com>.

Artículo recibido el 13 de julio de 2016 y aceptado para publicación el 15 de octubre de 2016. 
ABSTRACT: This paper undertakes a critical analysis about the corporate group in the Spanish legal system, including the case law and the scholarly opinions on the matter. The author emphasizes the legal dispersion in this field and defends the explicit recognition of the corporate group by the Spanish law. The author also deals with the definition of corporate group in other legal systems, like the Portuguese and the Brazilian, with especial regard to the so called hierarchical group or group by subordination.

KEYWORDS: Corporate groups, unit address, control, Spanish Law

\section{INTRODUCCIÓN}

La regulación de los grupos de sociedades en España es una asignatura pendiente. Los grupos son reconocidos por la legislación, la jurisprudencia y la doctrina, esta última le dedica gran atención, pero el legislador español no acaba de regularlos como tal, de forma sistematizada. Sin duda, existe una decisión de política legislativa detrás de esta carente regulación normativa. Sin embargo, a diferencia de otros ordenamientos jurídicos -el alemán, el portugués y el brasileño- en España se ha decidido que los grupos no deben ser regulados, pero la no regulación de los mismos, no imposibilita la existencia del grupo de sociedades a nivel nacional, muestra de la existencia de los mismos, como hemos mencionado al inicio, es el reconocimiento jurisprudencial que tienen los grupos de sociedades en la jurisprudencia española. ${ }^{1}$

La falta de regulación única de los grupos en la legislación española, no significa que ellos no se reconozcan, como hemos señalado antes, tanto la jurisprudencia, como la propia legislación española, reconocen su existencia e importancia ante la ausencia de un conjunto homogéneo de normas. Los grupos están presentes en el ámbito laboral, tributario, societario, contable,

Desde el punto de vista de la existencia y funcionamiento de los grupos de sociedades, no nos cabe la menor duda que ha sido obra de los tribunales, tanto en sede del derecho del trabajo con mayor profundidad, así como, en el derecho mercantil. Al respecto, Tribunal Supremo (STS 1954/2014), Audiencia Provincial Barcelona (SAP B 6634/2015), Tribunal Superior de Justicia de Galicia (STSJ GAL 7859/2015), Tribunal Superior de Navarra (STSJ NA 224/2015). 
siendo la normativa que los regula en cada uno de estos ámbitos, diferente y

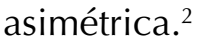

El grupo de sociedades es -según la mayoría de los autores ${ }^{3}$-la forma de concentración empresarial preferida por los operadores jurídicos, para obtener una dimensión de empresa óptima y afrontar los retos competitivos del mercado. ${ }^{4}$ En el ámbito positivo, la regulación de los grupos de sociedades en general suele presentar, entre otros, dos rasgos que encuentran explicación en la dificultad, ante la que se halla el jurista, de concebir en términos de abstracción y de regular situaciones que, como el grupo, constituyen ante todo una realidad económica. Si bien cabe afirmar que, salvo excepciones, las legislaciones contemporáneas suelen adolecer de la ausencia de una definición única y general de grupo de sociedades ${ }^{5}$, regulándose el mismo de forma sectorial. Esto se debe a la dificultad de abstracción del significado estrictamente empresarial del grupo y a la interdisciplinariedad de esta nueva forma de empresa.

En este sentido, el fenómeno de los grupos de sociedades, aunque satisface necesidades actuales de los operadores económicos, afecta a bienes jurídicos protegidos por diversos sectores del ordenamiento, como son: la libre competencia, los derechos de los accionistas minoritarios, de los trabajadores, los derechos de crédito de los acreedores, los derechos de los consumidores, la estabilidad del sistema financiero, entre otros. Pero, aunque su regulación especial, de conformidad con los principios que rigen cada rama del ordenamiento, sea necesaria para una adecuada protección de los específicos intereses afectados, se hace preciso, a la vez, una regulación general sobre grupos -tarea bastante dificultosa, incluso, para los ordenamientos comunitarios $^{6}$-, por lo menos una previa comprensión de las características esenciales de la figura. El análisis de éstas y, de las realidades económicas

2 Cabe destacar que si bien no existe una regulación única que regule el grupo de sociedades en el ordenamiento jurídico español, sí son reconocidos por diferentes áreas del Derecho. Vid. SebAstián (2009) p. 94, Embid (2003) pp. 38-41.

3 Vid. entre otros, Embid (1996) p. 1225, Fernández (1995) pp. 1221 y 1222.

4 En este sentido, SÁNCHEZ (2000) p. 11, se pronuncia respecto de la necesidad de mejora y perfeccionamiento técnico de las estructuras de unidades de producción.

5 En este sentido, cabe reconocer la regulación específica al fenómeno de los grupos de sociedades por algunos ordenamientos jurídicos nacionales, tales como, la Ley de sociedades por acciones alemana de 1965 (Aktiengesetz), hay traducción al español con estudio preliminar por EmвіD (2010); la Ley de Sociedades por acciones brasileña de 1976 y el Código de Sociedades Comerciales portugués de 1986.

$6 \quad$ Vid., EмBID (1989) pp. 357-417. 
sobre las que se asienta el fenómeno, contribuirá a evitar la diversidad de terminología jurídica equívoca, traducible en muchos casos en una confusión de la figura con situaciones intermedias de vinculación empresarial, cuya presencia, en diversa medida y con diversos grados, constituye el segundo de los rasgos que caracteriza a las legislaciones contemporáneas en la materia.

En la regulación legal de los supuestos de grupo se tiende a confundir esta figura con situaciones de control societario, de influencia dominante, -tal y como sucede en el art. 42 del Código de Comercio español (en adelante C.Com ${ }^{7}$ - o de participación significativa en el capital, entre otras. Y, en el mejor de los casos, el legislador adopta como técnica de regulación, el establecimiento de presunciones de existencia de grupo de sociedades sobre

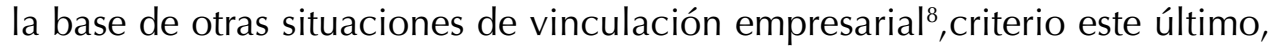
no desechable siempre que se tenga presente que el supuesto de hecho de la presunción es sólo indicio de una situación de vinculación mucho mayor -que implica el funcionamiento de una empresa que trasciende las estructuras societarias- y en tanto no se traduzca el mecanismo legislativo en una elaboración de listados que impliquen una duplicidad de términos. ${ }^{9}$ Así pues, todo intento de diferenciación del grupo, aunque no pueda ser concluyente al tratarse de una realidad cambiante, influirá en una regulación de éste, y de las demás relaciones inter-empresariales de acuerdo a su importancia, ya que no se produce en todas ellas el mismo nivel de concentración económica, ni de riesgo para los intereses comprometidos.

Los grupos de sociedades, al tener entre sus causas la necesidad de organización de empresas de grandes dimensiones, cuya viabilidad supera el tradicional binomio "empresa-persona jurídica", predominan en el ámbito de las sociedades mercantiles, fundamentalmente capitalistas, siendo en su

$7 \quad$ Si bien el propio art. 42 Código de Comercio establece una delimitación exclusiva del grupo meramente de control, es cierto que en determinadas ocasiones, en cambio, se reconoce en el grupo la existencia de una "unidad de decisión" como establece el art. 4 de la Ley del Mercado de Valores (en adelante LMV), lo que es presumible en una situación de control, a estos efectos, vid., EMBID (2003) pp. 22-24; así reconoce también, EMBID (1996) p.1229, al plantear que, "para el legislador español, no existe diferencia apreciable entre situación de control y grupo".

8 En determinados casos no estamos ante un desconocimiento de la diferencia entre control y grupo, sino que el legislador simplemente se ha valido de presunciones ante la imposibilidad de concretar realidades de naturaleza económica. Al respecto EMBID (1996) pp. 1239 y 1240, señala que como la dirección unitaria no es un concepto fácil de precisar, cabe presumir la existencia de grupo en presencia de un mero supuesto de control.

$9 \quad$ Vid., Ramírez (2001) pp. 630-632. 
mayoría sociedades del tipo anónima ${ }^{10}$, con una amplia base económica y personal.

Por todo lo anterior, en el presente trabajo, analizamos el grupo de sociedades desde el punto de vista doctrinal, partiendo desde las diferentes nociones del concepto de grupo, así como las referencias en materia de grupos en otros ordenamientos jurídicos, el grupo jerárquico o por subordinación, clasificación ésta, que no siendo la única de grupos de sociedades, consideramos la de mayor relevancia para nuestro trabajo. ${ }^{11}$ Lo que nos permitirá conocer el interior del grupo de sociedades, sin abarcar más allá del marco objeto de estudio del presente trabajo.

\section{LOS GRUPOS DE SOCIEDADES: UNA IMPRONTA NECESARIA EN EL OR- DENAMIENTO JURÍDICO ESPAÑOL}

La doctrina ${ }^{12}$ más autorizada respecto al tema ha manifestado siempre los elementos que definen al grupo desde el punto de vista económico, la relación de dependencia ya sea directa o indirecta de una o varias sociedades dependientes respecto a otra dominante y el ejercicio de una dirección económica única ${ }^{13}$ o unitaria por ésta -sociedad dominante- sobre el conjunto de los demás. Este último elemento "el ejercicio de la dirección económica unificada" permite la constitución de una nueva unidad empresarial distinta de la diversidad de las formas jurídicas, la cual, a su vez, tendrá intereses propios que pueden o no diferir de las sociedades que conforman el propio grupo. ${ }^{14}$

Uno de los fenómenos más importantes en el ámbito de las sociedades mercantiles es la aparición de grupos de sociedades, en los que existe

10 No siendo ésta una excepción, ya que, al referirnos a grupos de sociedades, entendemos éste en el sentido amplio, abarcando también otros tipos societarios, como sociedades cooperativas e incluso sociedades civiles, siempre con sus oportunas salvedades, al respecto ЕмвіD (2003) p.63.

11 Distinción ésta reconocida por la doctrina más actual en materia de grupo de sociedades, al respecto, entre otros, EmBID (2003) pp. 6-8, GIRGADO (2001) pp.145-148.

12 Vid., ЕмвіD (1989) p. 376.

13 En este sentido, Boldó (2006) p.329, reconoce que el elemento de la dirección económica única caracteriza típicamente a los grupos y les permite distinguirlo de otras uniones de sociedades.

14 Ibídem., defiende que en este sentido puede existir una preponderancia del propio grupo respecto al resto de las sociedades que lo integran, específicamente sobre el interés social particular de éstas, trayendo como consecuencia un replanteamiento de las normas tradicionales del Derecho de sociedades. 
una sociedad dominante, y una o más sociedades dominadas, bien directamente, o indirectamente a través de otras entidades del grupo. El control se ejerce normalmente detentando la mayoría -o en su caso la totalidad- de los derechos de voto en la junta de socios, o excepcionalmente, a través de pactos con socios minoritarios que permiten la designación por la dominante de la mayoría del órgano de administración. Como bien comentamos en la introducción del presente capítulo, en el Derecho Español no existe una regulación general de los grupos de sociedades. En el ámbito del derecho de sociedades, la única mención a la que la Ley de Sociedades de Capital (en adelante LSC) hace referencia a los grupos de sociedades es en su art. 18, el cual se limita únicamente a remitirnos al art. 42 del C.Com.

\section{Concepto de grupo de sociedades; una visión desde el derecho comparado y el derecho español}

\section{A) Aproximación al CONCEPTO DE GRUPO DE SOCIEDADES}

La definición de grupos de sociedades no es una cuestión pacífica única en el derecho español, ni en el derecho comparado. Si bien, existe unanimidad en la doctrina ${ }^{15}$ en considerar que, un grupo es un agregado empresarial integrado por diversos sujetos de Derecho que, sin perjuicio de su personalidad jurídica propia, quedan sometidos en su actuación en el mercado a una dirección económica unificada, ejercida por la entidad cabecera del grupo. Sin embargo, la concurrencia o no de los elementos que caracterizan la existencia de un grupo de sociedades -los cuales hemos referenciado en el epígrafe anterior- determinan la distinción conceptual entre un concepto estricto y uno amplio del grupo. El primero de ellos, necesitaría de la existencia de una doble relación de dominio, dependencia y sometimiento a una dirección unitaria, la falta de uno de ellos contribuye a la inexistencia de la noción de grupo, lo que hace prevalecer como requisito indispensable la dirección unitaria derivada de la relación de dependencia. ${ }^{16} \mathrm{El}$ segundo, o sea, el concepto amplio de grupos, trae consigo, por una parte, la eliminación del concepto

15 En este sentido se han pronunciado, entre otros, LópEz (2014) p. 31, EMBID (2003) p. 3.

16 Al respecto, Boldó (2006) pp.329 y 330, reconoce que el concepto estricto de grupo puede partir de una segunda restricción: limitar tal noción sólo a los grupos compuestos por sociedades, dejando de lado la posible integración de empresarios individuales y de otras figuras asociativas con o sin personalidad jurídica. De esta forma se excluyen los llamados grupos por coordinación, vid., SÁNCHEZ (1979) p. 48. 
de dependencia ${ }^{17}$, y por otra, una sustitución del criterio de dirección unitaria por el de interés común del grupo ${ }^{18}$ respecto al primero.

A la hora de acatar el concepto jurídico del grupo de sociedades es preciso reconocer las múltiples variantes que entraña este fenómeno. Como bien hemos referenciado antes, nos encontramos con el desafío de la independencia jurídica-dirección unitaria ${ }^{19}$ de las sociedades que conforman el grupo. De ahí que, tal y como reconoce Fernández Markaida "si consideramos que el derecho de sociedades ha venido desarrollando su normativa de acuerdo con el principio de independencia jurídica y económica de las sociedades"20, es de fácil comprensión que la mera existencia del grupo colisionará, prima facie, con un principio básico y tradicional de aquella rama del derecho, la de sociedades.

Resulta necesario resaltar la gran diversidad estructural que caracteriza a los grupos de sociedades. En la práctica podemos encontrar una multiplicidad de clasificaciones de grupos no excluyentes una de otras: grupos por subordinación o jerárquicos; grupos de estructura paritaria o por coordinación; grupos centralizados o descentralizados; públicos o privados; contractuales o fácticos; de tamaño pequeño, mediano o grande ${ }^{21}$; etc. Lo que dificulta notablemente la labor del legislador, ya que obliga a éste a articularlos de forma diferente según su variedad tipológica. Unido a la gran diversidad tipológica de los grupos de sociedades, debemos tener presente que el fenómeno grupal se manifiesta en una gran variedad de sujetos, físicos o jurídicos, públicos o privados cuyas características deben ser tenidas en cuenta por el legislador, así como la gran heterogeneidad de sectores económicos. ${ }^{22}$

17 Respecto a éste, se señala que lo que verdaderamente interesa para llegar a una noción de grupo es el hecho de la dirección unitaria, o sea, se trata de que la unidad empresarial agrupada ha perdido su autonomía y capacidad para decidir autónomamente sus procesos empresariales. Y para ellos no es necesario acudir a la noción de dependencia, vid., BolDó (2006) p. 330.

18 De esta forma es el llamado interés del grupo el que permite individualizar la noción de grupo y justificar su regulación, al respecto, Ibídem.

19 Vid., ídem., p. 332.

20 Al respecto, FernándeZ (2001) p. 151.

21 Al respecto, vid. una clasificación completa de los grupos de sociedades en DuQUE (1996) p. 398.

22 Como puede ser, a modo de ejemplo, en el sector financiero, donde por su especial connotación, la Administración controla y vigila el fenómeno de integración empresarial de este tipo de sociedades. 
Debemos tener presente que la noción de grupo reúne una serie de elementos, como son: el control, la dirección unitaria o el interés del grupo ${ }^{23}$, los cuales, al no estar regulados en normas positivas del ordenamiento jurídicoespañol, y responder a conceptos jurídicamente indeterminados, tampoco ayudan a una correcta definición de este fenómeno. Hasta aquí, podemos apreciar que el primer problema que nos encontramos respecto al Derecho de grupos es referente a la propia conceptualización del mismo, con otras palabras, a la delimitación del concepto de grupo, muestra de ello lo es, sin duda alguna, la diversidad de corrientes doctrinales al respecto. ${ }^{24}$

Conviene resaltar que en el presente trabajo partimos siempre de una visión dinámica de los grupos de sociedades. Por lo que, desde esta perspectiva, la mera existencia del elemento de control no conforma por sí sola el grupo de sociedades; es un instrumento necesario en cuanto a los grupos por subordinación se refiere, pero no es suficiente para la calificación del grupo. De ahí que, podamos resaltar como elementos conformadores del concepto de grupo los siguientes; pluralidad de empresarios independientes, el instrumento de obtención del poder de dirección y la dirección unitaria. ${ }^{25}$

Pese a la carencia de personalidad jurídica en los grupos de sociedades, tanto la doctrina ${ }^{26}$ como la jurisprudencia ${ }^{27}$ han centrado sus esfuerzos en el estudio de este fenómeno de empresa moderna. Ya que, como consecuencia de la dirección económica unitaria que preside el funcionamiento de los grupos, se pueden derivar perjuicios para las propias sociedades integrantes del grupo y terceros, que requieren de la correspondiente respuesta jurídica a fin de proteger los posibles intereses en juego.

\footnotetext{
23 Al respecto vid. apartados I.2 y $\mathrm{I} .3$ del presente trabajo.

24 Por una parte, nos enfrentamos a la doctrina que sigue una concepción estricta del grupo, los cuales se conforman mediante los mecanismos de dependencia y dirección unitaria, lo que contradice el principio de independencia jurídica del Derecho de sociedades. Y, por otra parte, nos encontramos la doctrina que defiende una concepción más amplia del grupo, el cual para que exista basta con que se ejerza una dirección unitaria de todas las sociedades, supuesto éste que abarcaría la regulación de los grupos por subordinación, los cuales se caracterizan por la ausencia de dependencia societaria. A ambas posiciones nos hemos referido en el inicio del presente epígrafe. Vid. Fernández (2001) p. 154.

25 A tales efectos, FerNÁndez (2001) pp. 156-173, reconoce dichos elementos como notas delimitadoras o elementos característicos que jurídicamente constituyen el concepto de grupo.

26 Vid., Embid (2003) p. 31, Boldó (2006) p. 334.

27 Vid., sentencias del Tribunal Supremo (STS 3166/2014, STS 735/2014) y Audiencia Provincial Barcelona (SAP B 6634/2015).
} 
Este sistema ya no se presenta sólo como el resultado de un proceso de concentración empresarial, sino también, como del de descentralización o desconcentración de actividades de una empresa que devino demasiado grande, o que, por razones de dispersión geográfica o de especialización, requiere la creación de sujetos societarios separados, sin por ello dejar de constituir una unidad económica y de decisión. Es el elemento de la "dirección económica unitaria" -tal y como hemos referenciado en epígrafes anteriores- ejercida por un sujeto de acuerdo a una estrategia o interés común a todos los miembros del grupo, el elemento esencial de éste. ${ }^{28}$

En el derecho comparado son pocos los ordenamientos que ofrecen una definición y regulación de este fenómeno. ${ }^{29}$ Resulta interesante el ejemplo de la Unión Europea, en cuyo seno se formó, hace más de treinta años, el propósito de elaborar unas normas específicas sobre los grupos de sociedades, promulgando al efecto dos directivas: una, sobre los aspectos contables, y otra, sobre la vertiente jurídico-material. ${ }^{30}$ La primera se aprobó, efectivamente, en 1983 y fue objeto de recepción legislativa por los diversos países de la Unión; en España, en concreto, encontramos sus huellas en diversos preceptos, de entre los que destacan los artículos 42 al 49 del C.Com.

Sin embargo, ordenamientos jurídicos como Alemania, Portugal y Brasil, los cuales han realizado un tratamiento sistemático de la materia ${ }^{31}$, constituyen referentes internacionales en materia de grupo. Motivos por los cuales, en los epígrafes siguientes, haremos una breve referencia a los ordenamientos jurídicos brasileño y portugués respecto a la materia objeto de estudio en el presente capítulo: los grupos de sociedades.

28 Vid., LÓPEZ (2014) p. 32.

29 Vid. nota supra 5.

30 La directiva sobre el régimen jurídico-material de los grupos fracasó, existiendo además voluntad por parte de la propia Unión Europea de no Ilevarla adelante. Sin embargo, pese a la aprobación de dicha directiva, la propia Unión Europea transfiere a los Estados, sobre la base del principio de subsidiaridad, la competencia legislativa esencial para fijar sus bases fundamentales, siendo prueba de ello, el Informe Winter (noviembre de 2002), elaborado por un relevante equipo de juristas europeos, en el que se fijan las pautas para la regulación de las sociedades mercantiles en el ámbito europeo. Al respecto, EMBID y SALAS (2005) p.27.

31 Existen otros Estados, Francia e Italia, los cuales también le han prestado atención a la figura de los grupos, pero desde un punto de vista parcial y fragmentaria, renunciando a la ordenación sistemática del grupo, considerando suficiente los principios generales del Derecho de sociedades a los efectos del tratamiento de los grupos, vid. GiRGADo (2001) p. 20. 


\section{B) BREVE REFERENCIA AL GRUPO DE SOCIEDADES EN EL ORDENAMIENTO BRASILEÑO}

En el ordenamiento jurídico brasileño, en su Ley de Sociedades Anónimas (en adelante LSAB), específicamente en el artículo 265, establece que "una sociedad controladora y sus controladas pueden constituir, en los términos de este capítulo, grupo de sociedades, mediante convención por la cual se obligan a cambiar recursos o esfuerzos para la realización de los respectivos objetivos, o a participar de las actividades o empresas comunes". De cuya definición podemos determinar las características más significativas de la regulación del concepto de grupos en Brasil, destacando las siguientes; la adopción del criterio contractual de regulación de grupos de sociedades, denominándose el contrato de convención; se reconoce y regula el grupo por subordinación, ya que el propio precepto parte de la existencia previa de un control; la mera existencia de un control societario, que no supone la constitución de un grupo de sociedades, sino que se trata de dos conceptos diferentes ${ }^{32} y$; por último, no hay una referencia a la dirección unitaria. ${ }^{33}$

Sin embargo, consideramos destacable la regulación que la legislación brasileña efectúa en cuanto a la organización interna del grupo, como son la administración y organización. La propia ley se limita a establecer unos principios mínimos de organización del grupo ${ }^{34}$, cuyo precepto infiere que la estructura organizativa del grupo, ofrecida por la ley -basada en la sociedad anónima- es de carácter dispositivo. ${ }^{35}$

Otro de los elementos diferenciadores de LSAB, respecto al grupo, es la regulación que hace respecto a la legitimación del poder de dirección sobre el grupo ${ }^{36}$, o sea, la obligación de acatar tal poder por las sociedades filiales, los límites del mismo, así como la reparación de perjuicios ocasionados por el ejercicio extralimitado de tal poder mediante la concesión de acciones al socio externo, o minoritario, contra los administradores de su sociedad y frente a la sociedad dominante. Es de destacar también que la LSAB -a diferencia de los elementos positivos reconocidos anteriormente- no ha prestado atención a los grupos fácticos, los mismos no se encuentran regulados,

32 Vid., FERNÁNDEZ (2001) p. 81.

33 En este sentido, EмвіD (1989) p. 81, destaca la posible confusión del legislador brasileño respecto al concepto de control y de dirección unitaria.

34 Al respecto, el art. 272 LSAB establece que "la convención de constitución del grupo deberá definir la estructura administrativa del grupo de sociedades, pudiendo crear órganos de deliberación colegiada y cargos de dirección general".

35 Vid., FERNÁNDEZ (2001) p. 83.

36 Vid. art. 273 de la LSAB. 
ni definidos en la propia ley. ${ }^{37}$ También podemos apreciar una ausencia de regulación de los grupos por coordinación en la ley brasileña, el legislador brasileño no ha pretendido contemplar un tipo de grupo que se caracterice por la dirección unitaria sin relación de dependencia.

\section{C) LOS GRUPOS DE SOCIEDADES EN EL ORDENAMIENTO JURÍDICO PORTUGUÉS}

El 2 de septiembre de 1986 se publica en el Diario de la República de Portugal el Decreto-Ley n 262/86, por el que se aprueba el Código de Sociedades Comerciales (en adelante CSCP). El mismo tiene en común con la LSAB, entre otras cosas, el principio contractual de constitución de los grupos de sociedades. ${ }^{38}$

El CSCP se caracteriza por la taxatividad o carácter cerrado de las situaciones jurídicamente consideradas de grupo, como por la limitación de su ámbito de aplicación, quedando éste restringido a sociedades anónimas, limitadas y en comanditas por acciones con sede en Portugal, siendo éste último criterio de ubicación o localización de las sociedades, considerado como una forma de excluir la protección de las sociedades filiales -de otra dominante- con sede fuera de Portugal. No obstante, se excluye también la posibilidad de que otros tipos sociales o las propias personas físicas participen en este sistema de integración empresarial, ni siquiera como empresa dominante. ${ }^{39}$

Pero al igual que ocurre en el Derecho de grupos en Brasil, el CSCP parte de la formación gradual del grupo de sociedades, estableciendo un proceso que desarrolla a través de varios supuestos, como son, (i) las sociedades de simple participación, (ii) sociedades en relación de participaciones recíprocas, (iii) sociedades en relación de dominio, y (iv) sociedades en relación de

$37 \quad$ Si bien es cierto que la tipificación de dichas figuras plantea los mismos problemas que el grupo creado mediante contrato de convención, al que la ley no destina normas protectoras del patrimonio social, ni de los acreedores o los accionistas externos al grupo, art. 276 de la LSAB, cuya omisión supone el punto más vulnerable de toda la regulación en materia de grupos.

38 Aunque FERNÁNDEZ (2001) p. 90, reconoce que el CSCP tiene muchos más vínculos con la regulación de los grupos de sociedades en el ordenamiento jurídico alemán que con el brasileño. Inspirándose aquel en el proyecto de novena Directiva de la Comunidad Económica Europea de 1984.

39 Al respecto, ANTUNES (1993) p. 25, refiere que esta norma se trata en su conjunto de "un derecho de las sociedades subsidiarias o dependientes que no contiene ninguna regulación relevante concerniente a la sociedad madre o al grupo como tal". 
grupo. En los tres primeros supuestos, rige el principio de supremacía del interés de las sociedades participadas o dominadas, ya que se considera que todavía no existe una unidad económica. Mientras que una vez alcanzada la constitución del grupo, el contrato de subordinación otorga a la sociedad directora el derecho a dirigir o dictar órdenes a las sociedades dominadas, las cuales, salvo excepciones, tienen el deber de acatar. Sin embargo, el resto de los supuestos, dígase el tercero y cuarto, resultan los más interesantes. El primero de éstos se caracteriza por incluir la regulación de los grupos fácticos, entendidos como aquellos con relación de dependencia, pero sin contrato de subordinación. Por lo que resulta decisivo en este sentido el concepto de control o influencia dominante, en los que la doctrina ${ }^{40}$ reconoce tres presupuestos para su establecimiento, siendo a tales efectos, el presupuesto de potencialidad, el de estabilidad y el de amplitud.

Podemos afirmar que el CSCP no le presta atención al grupo de hecho, no regula el sistema de protección dirigido a accionistas externos o acreedores, tampoco ha previsto disposiciones especiales en materia de responsabilidad de este supuesto fáctico. ${ }^{41}$ Respecto a los grupos de sociedades, el CSCP regula tres categorías, las cuales son, (i) los grupos constituidos por dominio total $^{42}$, (ii) el contrato de grupo paritario ${ }^{43}$, (iii) el contrato de subordinación. ${ }^{44}$

40 Al respecto, FERNÁNDEZ (2001) p. 92, reconoce que en el presupuesto de potencialidad no es necesario que la influencia sea efectiva, sino que basta con que lo sea potencialmente, respecto al presupuesto de estabilidad, reconoce que se requiere una prolongación temporal de la influencia dominante por la sociedad rectora del grupo, y como el presupuesto de amplitud, reconoce que la influencia debe ser amplia de forma que pueda surtir efectos en toda la unidad patrimonial del grupo.

$41 \quad$ Vid., Antunes (1995) p. 370.

42 El contrato de dominio total se encuentra regulado en los arts. 488-491 del CSCP, el cual se reconoce que queda a medio camino entre el contrato de subordinación y la fusión, naciendo jurídicamente ex lege y no por la voluntad de las partes, bien inicialmente o posteriormente, supuesto en el que el problema se centra prioritariamente a la hora de esclarecer los casos de participación indirecta de la sociedad dominante.

43 La legislación portuguesa no le dedica un régimen propio, al igual que en el derecho brasileño, pese al reconocimiento que la propia ley hace del grupo paritario o por coordinación.

44 El contrato de subordinación supone un negocio jurídico bilateral, sirviéndole como elementos de soporte y fundamento: la gestión social unitaria y exclusiva, y la subordinación al interés del grupo. Este contrato se encuentra regulado en el art. 493 del CSCP. 


\section{D) UNA MIRADA AL GRUPO DE SOCIEDADES EN EL ORDENAMIENTO JURÍDICO ESPAÑOL}

El ordenamiento jurídico español en lo que a grupo de sociedades se refiere, se caracteriza por la carencia de un cuerpo normativo suficiente y la dispersión en preceptos aislados en diferentes sectores jurídicos. Por lo que el tratamiento diferenciado de los grupos de sociedades en cada sector, dificulta o impide en gran medida la constitución de un Derecho de grupos. De ahí que podamos constatar el abandono en que el legislador societario ha dejado esta figura societaria.

Motivos por los cuales, en el ordenamiento jurídico español, no existe en estos momentos una noción unitaria y definida del grupo de sociedades. La noción básica del grupo se encuentra en el artículo 42 C.Com., el cual regula una noción de grupo que alberga única y exclusivamente la finalidad de imponer a la sociedad dominante la obligación de formular las cuentas consolidadas del grupo, comportando las mismas responsabilidades para la sociedad y para sus administradores. Coincidimos con Fernández Maikada ${ }^{45}$ respecto a que, el legislador ha recogido el concepto de "grupos consolidables" más que el de "grupo de sociedades", fijando así los mecanismos para presumir la existencia de una relación de dominación entre dos o más sociedades. Por lo que pudiéramos resumir que esta norma ha fijado lo que la doctrina ha venido a denominar el "perímetro de consolidación". ${ }^{46}$

La noción de grupo consolidable recogido en el artículo 42 C.Com., es el núcleo actual de la definición del grupo de sociedades en nuestra legislación mercantil y societaria. A él se remiten, expresa o implícitamente, los demás preceptos que delimitan la relación de dominio o de grupo, tal es el caso del artículo 18 LSC y el artículo 4 LMV, entre otras, quedando solamente constreñido el contenido del artículo a determinados supuestos. Lo que permite que el concepto de grupo de sociedades esté circunscrito a la idea de control, sin perjuicio de que algunas de las técnicas de control, recogidas en el mismo, son prácticamente inoperantes, o se encuentran subsumidas en otras. Por lo que, al contrario de lo establecido en el artículo $4 \mathrm{LMV}$, se omite el concepto de control externo, entendido como el basado en un contrato o en una cláusula estatutaria, no existe tampoco una referencia expresa a la figura del control conjunto, es decir, la situación de dominación en la que existe pluralidad de sociedades controladoras o dominantes, concepto éste que podemos entre ver en el propio artículo 4 LMV.

\footnotetext{
45 Vid., FeRnÁndez (2001) p. 219.

$46 \quad V i d .$, Rojo (1996) p. 467.
} 
Resulta necesario reconocer que la circunstancia determinante de la constitución del grupo en la LMV, en contraposición con el artículo 42 C.Com., es la denominada "unidad de decisión", también llamada "dirección única o unitaria", situación que se presume existente, iuris et de iure, por el ejercicio efectivo de un control o la mera posibilidad de ejercerlo, introduciendo en este último caso la figura del control potencial. Por otro lado, debe destacarse que el legislador ha utilizado la denominación de "grupos de entidades", no de sociedades, ampliando así la noción de grupo a otras formas jurídicas diferentes de las mercantiles y que no aparecen incluidas en el artículo 42 C.Com.

Como podemos apreciar, en el ordenamiento jurídico español existe una diversidad respecto a la definición de grupos de sociedades, teniendo en cuenta la pluralidad de normas que se refieren a la figura del grupo. Sin embargo, el único punto en común entre las diferentes definiciones legales existentes, consiste en referir la idea de grupo exclusivamente al concepto de control, esto es, a lo que serían los grupos de dominación o por subordinación, compuestos por una sociedad dominante y otra dominada.

Tal y como referenciamos antes, mientras que en el ámbito jurídico mercantil la noción de grupo descansa en el elemento "control", efectivo o potencial, el cual se obtiene por la posesión mayoritaria de los derechos de voto o la facultad de nombrar o destituir a los miembros del órgano de administración. En otros ámbitos, por ejemplo, el tributario, referente al Impuesto sobre Sociedades ${ }^{47}$, exige que la sociedad dominante tenga una participación, directa o indirecta, de al menos el 90 por 100 del capital social de las sociedades dependientes.

Si bien es cierto la relevancia que tiene la regulación de los grupos de sociedades en los ordenamientos jurídicos alemán, portugués y brasileño, respecto al resto de los ordenamientos carentes de dicha regulación, teniendo en cuenta la importancia del grupo en el ámbito no sólo mercantil, sino también laboral, fiscal, entre otros; los mismos no son ajenos a fallos, los cuales han sido señalados por la doctrina. ${ }^{48}$

Coincidimos con Boldó cuando sintetiza como principales fallos en los intentos de regulación unitaria de los grupos: "el desconocimiento por el legislador del significado estrictamente empresarial del grupo, la fatal contraposición entre el interés del grupo y el interés de las sociedades dependientes

$48 \quad$ Vid., Boldó (2006) p. 332 
y, por último, la exclusiva comprensión del régimen jurídico de aquél como un conjunto de normas de carácter protector" ${ }^{49}$

En fin, en el Derecho Español, el fundamento que ha servido para conseguir una cierta armonización y convergencia normativa es la llamada "unidad de decisión". El concepto de grupo, como hemos señalado anteriormente, se encuentra contenido en el actual artículo 42 C. Com., que se acerca claramente a la noción germana de grupo, muy estrechamente relacionada con la noción de control, sin perjuicio de que éste conlleva en la práctica la unidad de dirección, aunque no tenga que ser así necesariamente en todo caso. ${ }^{50}$

El propio artículo 42 C.Com. define al grupo en función de la existencia de "la unidad de decisión", la cual se presume siempre y cuando exista una "relación de control". ${ }^{51}$ En este sentido, el precepto responde a las disímiles peticiones que, de forma unánime, se venían reflejando en la doctrina ${ }^{52}$. Lo que no le resta importancia, cuando de grupo se trata, a la dirección económica unitaria como elemento de vital importancia en materia de grupos de sociedades.

No obstante, en la propuesta de Código Mercantil que ha sido presentada por la Comisión de Codificación al Ministerio de Justicia, la misma opta por un concepto de grupo de sociedades amplio, articulado en torno a la existencia de una unidad de dirección como elemento definitorio del grupo (entendida, en términos generales, como la presencia de unas políticas financieras y económicas unificadas o centralizadas entre las distintas sociedades del grupo), en el cual tienen cabida tanto los grupos verticales o por subordinación, como los horizontales o por coordinación, sea cual fuere el mecanismo por el cual el grupo se ha configurado. Sin embargo, la noción de control continúa siendo relevante en la medida en que el control de una sociedad sobre otra supone la presunción, iuris tantum, de la presencia de una dirección unitaria ejercida por la controlante. ${ }^{53}$ Se señala, por si fuera necesario, que el grupo de sociedades carece de personalidad jurídica, por lo cual éste, pese a su regulación, no se constituiría como sujeto susceptible de imputación de relaciones jurídicas.

\footnotetext{
$49 \quad$ Ídem., p. 333.

$50 \quad V i d .$, LÓPEZ (1996) p. 31.

51 Vid., Boldó (2006) p. 336.

52 Ídem.

53 Vid. Paz-Ares (2014) p. 89.
} 
Aunque los redactores de la propuesta de Código Mercantil no se hayan aventurado a edificar la noción de grupo sobre la presencia de una "unidad económica" o "empresa plurisocietaria" como la más avanzada doctrina planteaba, la propuesta mejora con creces la definición actual contenida en el artículo 42 del C.Com. (a la cual se remite el artículo 18 de la LSC), que resulta insuficiente. Recordemos que al albor de la regulación vigente se corre el riesgo de considerar "grupo" a vinculaciones de sociedades que estrictamente no lo son, ya que no actúan bajo una unidad de dirección; el artículo 42 del C.Com. - desde su actual redacción dada por la Ley n 16/2007 - construye la definición de grupo en torno al "control" o a la "posibilidad de control", ignorando el requisito de la dirección unitaria o "unidad de decisión" sobre el que gravitaba su redacción anterior. Por otro lado, mayoritariamente se entiende que la actual concepción excluye tanto a los grupos por coordinación como aquellos por subordinación cuya "matriz" sea una persona física (caso muy frecuente) u otro tipo de persona jurídica.

Si bien no constituye objeto de análisis en el presente trabajo el derecho de la competencia, no podemos negar la relación existente entre éste y el derecho de sociedades, más específicamente con los grupos de sociedades. A modo de ejemplo, podemos citar la sentencia del Tribunal de Justicia de la Unión Europa (en adelante TJUE) en el caso Akzo Nobel NV y otros contra Comisión de las Comunidades Europeas (2009, asunto C-97/08) (4) $^{54}$ confirmó que el hecho de que una sociedad estuviese completamente participada por su matriz da lugar a una presunción iuris tantum que permite atribuir responsabilidad a esa matriz por la infracción de las normas de defensa de la competencia cometida por su filial.

\section{Dirección económica unitaria y administración de hecho en los grupos de sociedades}

La unidad de dirección económica del grupo opera a través de una red de mando jerarquizada, donde los protagonistas suelen ser los órganos de administración de las sociedades filiales, que actuarán siguiendo los dictados del órgano de dirección de la sociedad dominante titular de la dirección unitaria. De esta forma, la ejecución de la política económica unitaria queda en manos de los administradores, siendo el papel de las juntas generales simplemente ignorado desde el punto de vista material, lo que se traduce en un aumento de poder de los órganos de administración de las sociedades filiales

54 Esta sentencia abrió un debate sobre el enfoque adoptado por el TJUE sobre este asunto y las posibilidades reales de que una matriz pueda aportar de manera exitosa pruebas que desvirtúen la presunción de responsabilidad 
y, por ende, en una pérdida mayor del poder del órgano representativo de los socios, reemplazando el principio de separación de poderes por el de la acumulación de poder.

El empleo del poder de dirección unitaria puede orientar a la sociedad filial a la consecución de un interés empresarial distinto al suyo, lo que puede traducirse, en no pocas ocasiones, en un daño patrimonial para la sociedad e indirecto para los acreedores. Ello sucede normalmente porque el Derecho de sociedades les compele a llevar los negocios de su sociedad de acuerdo al mejor interés de ésta, bajo la amenaza de incurrir en responsabilidad ante los accionistas, los acreedores y la sociedad misma, pero, por otro lado, estos mismos administradores se encuentran compelidos a seguir las instrucciones que provienen de la matriz y que persiguen un interés global del grupo, cayendo en una doble presión, planteándose este mismo conflicto en la junta general de socios.

Sectores de nuestra doctrina, han pretendido extender el ámbito subjetivo del régimen de responsabilidad de administradores para aplicarlo a los administradores de la sociedad dominante, o a ésta misma, sobre la base de acudir a la figura del administrador de hecho. ${ }^{55}$

Conviene precisar que la mera unidad organizativa y estratégica de las actividades de las distintas sociedades no implica necesariamente el ejercicio de las facultades de administración de las sociedades agrupadas. Por ello, no puede sostenerse que la simple existencia de un grupo de sociedades nos sitúe de manera directa y automática ante un supuesto de administración de hecho.

La unidad de dirección, a través de la que se manifiesta la legítima y lícita relación de control o dependencia que caracteriza al grupo, conlleva únicamente la coordinación de manera centralizada de las políticas estratégicas y organizativas de las filiales, persiguiendo la satisfacción del interés del grupo. Sobre la base de las anteriores consideraciones se encuadrarían, en el marco de la unidad de dirección, hechos frecuentes en la práctica de los grupos, tales como; el control de la composición de los miembros del Consejo de Administración de la filial o la circunstancia de que algunos miembros del Consejo de la matriz sean a su vez administradores de la filial interlocking directorates o el hecho de que, en ocasiones, las decisiones tomadas por los administradores de la filial en el ejercicio de sus facultades requieran, en 
atención a una lícita previsión estatutaria, la autorización de la matriz a través del ejercicio legítimo de sus derechos en la Junta General.

Para poder considerar a la matriz como administrador de hecho de la filial es preciso probar que, más allá de una injerencia legítima en la gestión de la filial, en el marco de una planificación estratégica y organizativa, establecida por la matriz en el seno del grupo, la sociedad matriz de manera directa y externa, con conocimiento y consentimiento de la filial, ha venido de hecho gestionando ésta de manera continuada y efectiva.

Esta viene a ser la doctrina del TJUE, recogida en el caso Eurofood IFSC Ltd. (2006, asunto C-341/04), el hecho de que las decisiones económicas de la filial puedan, o deban, ser controladas por la sociedad matriz cuyo centro de interés esté situado en un Estado distinto al de la filial, no es suficiente para desvirtuar la presunción sobre el lugar donde radica el centro de intereses principales del deudor. Ello acontecería sólo si la matriz actuara como administradora de hecho de manera pública y transparente, lo que no sucede en supuestos en que simplemente la sociedad matriz se encuentre, en virtud de su participación accionarial y de su facultad para nombrar administradores, en una posición de control respecto de la sociedad filial.

La calificación de la sociedad matriz como administradora de hecho de la filial, supondría que aquélla ha realizado un ejercicio de asunción directa, sistemática y no esporádica de la actividad estrictamente gestora de la filial. ${ }^{56}$ Lo que no acontece cuando la sociedad matriz ejerce una influencia sobre la gestión de la filial desde su posición de entidad matriz o dominante, como cabecera del grupo, con la finalidad de asegurar la planificación estratégica y las directrices de gestión a nivel de grupo. Es la apariencia en el tráfico lo que permitiría imputar los actos del administrador de hecho a la propia sociedad.

El Tribunal también afirma la responsabilidad de la sociedad dominante cuando la actuación seguida dentro del grupo genera una apariencia que justifica la confianza del tercero en tal consecuencia.

Supuesto distinto de los anteriores es aquel en que la matriz, en el marco de la dirección estratégica del grupo, ejerce su control mediante el impulso de determinadas decisiones perjudiciales para la filial, pero beneficiosas para el conjunto del grupo. No cabe en estos casos acudir a la figura del administrador de hecho, ni ocultar en fraude de ley, para suplir lo que constituye realmente una laguna en el ordenamiento jurídico español, consistente en la 
inexistencia de un derecho general de grupos en el que se contemple el ejercicio de la unidad de dirección, en perjuicio de socios y/o acreedores de una determinada sociedad filial integrada en el grupo.

Actuaciones como, por ejemplo, canalizar fondos de un sector de negocio hacia otro más rentable; cambios en la implantación territorial de centros de explotación de la titularidad de distintas filiales ubicadas en diferentes Estados; optar entre distintos tipos de negocios en situaciones de dificultad de financiación a nivel de grupo, etc. En estos casos no podemos hablar de administración de hecho, ni oculta en fraude de ley, sino simplemente una laguna por inexistencia de un derecho material o sustantivo de grupos que aborde precisamente esta casuística como sucede en otros ordenamientos de nuestro entorno.$^{57}$ Sin duda alguna, en cuanto a la dirección económica unitaria se trata, ocupa un papel relevante, también, el tipo de grupo de sociedades. De ahí que, teniendo en cuenta el objeto de estudio de nuestro trabajo, y en consonancia con el orden metodológico a seguir en el epígrafe siguiente, nos centraremos en el estudio de los grupos de sociedades jerárquico o por subordinación.

\section{El grupo de sociedades jerárquico o por subordinación, la relación de control o dominio}

Si bien hemos referido con anterioridad, las distintas definiciones de grupos de sociedades en las cuales prevalece como elemento esencial el conjunto de sociedades que, conservando su personalidad jurídica independiente, se encuentra sometida a una dirección económica unificada -única según otro sector de la doctrina ${ }^{58}$ - sobre la base del control. ${ }^{59}$ Sin embargo, cabe señalar que esta noción -al incluir como presupuesto la existencia de una relación de control-, conduce a restringir el concepto de grupo de sociedades a una sola de las categorías en que se divide el fenómeno; los grupos jerárquicos o por subordinación, teniendo en cuenta el tratamiento de los mismos en el Derecho positivo y en sede jurisprudencial y doctrinal ${ }^{60}$, estando en consonancia, a su vez, con el objetivo planteado en nuestro trabajo. Ya que

Vid., Alonso (2011) pp. 87-102.

58 Al respecto, EмвіD (1996) p. 1238, propone un concepto operativo de validez global que defina al grupo como "el conjunto de sociedades sometidas, sobre la base del control, al ejercicio de una dirección económica de carácter unificado".

59 En este sentido, vid. EMBID (1996) p. 1228, MARTínez-GıJón (1999) p. 210.

60 Si bien doctrinalmente se han reconocido la existencia de dos tipos de grupos, el grupo jerárquico o por subordinación y el grupo horizontal, paritorio o por coordinación, no es menos cierto que en el primero de ellos es donde existe cabida para el control societario, 
es en este tipo de grupos, donde con mayor frecuencia se ha tenido que hacer uso de la teoría del levantamiento de velo societario, no sólo para determinar la responsabilidad del hecho cometido, sino también para la validez y cumplimiento de la cláusula arbitral a aquellos no signatarios del convenio.

A la luz de la propuesta del nuevo Código de Comercio, art. 291-1.1a, existirá grupo: "cuando una sociedad esté sometida al poder de dirección de otra o cuando varias sociedades estén sometidas al poder de dirección unitario de una misma persona natural o jurídica, cualquiera que sea el fundamento de ese poder de dirección".

Es decir, hay grupo tanto en el caso de que una sola sociedad esté sometida al poder de dirección de otra, como en el caso de que varias sociedades se encuentren sometidas al poder de dirección unitario de otra sociedad o de cualquier otra persona natural o jurídica. Nótese que, en el segundo caso, el poder debe ser unitario, en el sentido de que ese poder recaiga conjuntamente sobre todas las sociedades. Por consiguiente, lo relevante en este tipo de grupos es la existencia de una relación de sometimiento o control por parte de un sujeto sobre una o varias sociedades. De este modo, se incluyen en la categoría de grupo las frecuentes estructuras en las que una persona natural la que se encuentra en el vértice y aquellas otras cuyo vértice es otra persona jurídica no sociedad, por ejemplo, una fundación. Sin embargo, se excluye del supuesto aquellas estructuras en las que una persona natural o jurídica no sociedad "somete" a una sola sociedad; es decir, para que exista "grupo de sociedades" debe, al menos, contarse con la presencia de dos o más sociedades.

Por ello, habrá siempre un sujeto -sociedad o no- denominado dominante o controlante, que será quien ejerce el poder de dirección sobre otras que se consideraran dominadas o dependientes; de ahí que el texto de propuesta de Código Mercantil matice que las normas relativas a la sociedad dominante serán de aplicación a cualquier persona natural o jurídica que ejerza el poder de dirección sobre sociedades dependientes (artículo 291-2).

Como decíamos anteriormente, lo relevante para la existencia de grupo es el sometimiento de una o varias sociedades a un poder de dirección, cualquiera sea el fundamento o el mecanismo por el cual se origine, por lo que, aunque lo más frecuente será que nos encontremos ante grupos de base societaria, el sometimiento al poder de dirección puede lograrse por muy

y que nos hemos referido en el presente epígrafe en relación directa con el elemento de la dirección unitaria. Entre otros, EMBID (2003) p. 7, RAMíreZ (2001) p. 631. 
diversos medios, como el contrato de dominación, disposiciones estatutarias, la identidad de administradores, etc.

Limitándonos al análisis de la figura de los grupos por subordinación, el control y las técnicas que hacen posible su obtención son los primeros indicios de la formación del grupo, pero no pueden identificarse con el mismo, ya que para hablar de grupo en sentido propio es necesaria la existencia de una dirección económica unificada, tal y como hemos sostenido con anterioridad. Es ésta, como "elemento unificador del grupo"61, la que le distingue de un mero supuesto de control societario. Por lo que, para comprender la realidad económica y jurídica que constituye el grupo de sociedades, es necesario aprehender los medios de adquisición del control, el control en sí mismo, la influencia dominante y el concepto de dirección unitaria.

El control es el punto de partida en la formación de un grupo por subordinación. Esto no significa que se subordine la importancia de tal situación a la posterior formación de esta nueva forma de empresa, ya que el control por sí mismo genera efectos jurídicos que el ordenamiento también tiende a detectar, regular y limitar. ${ }^{62}$ Sin embargo, la regulación de las situaciones de control se establece en la mayoría de los casos, en tanto se presume de una situación de grupo, como ocurre en el supuesto de la imposición del deber de consolidación contable según el método de integración global. ${ }^{63}$ Por este motivo, a los efectos del presente trabajo, interesa el análisis de la noción de control como presupuesto de la formación de un grupo de sociedades jerárquico o por subordinación y, como supuesto de hecho sobre el que suele recaer la presunción de su existencia.

Hablar de grupo de sociedades es hablar de una pluralidad de entidades independientes jurídicamente, pero que desde la perspectiva económica mantienen una relación de dependencia ${ }^{64}$, de forma que la libertad de delinear sus directrices de gestión económica se encuentra mermada, contemplando el grupo desde esta perspectiva, el elemento del "control", como uno de sus componentes, implicaría un respeto formal de la organización -legal o estatutaria- de las personas jurídicas que lo integran. Por este motivo, el

\footnotetext{
61 Vid., ЕмвіD (1996) p. 1227, ЕмвіD (2003) pp. 9-13, 45, 54.

62 Vid., EMBID (1996) p. 1235.

${ }^{63}$ Este método se impone también a las sociedades que se encuentran en el supuesto del art. 42.1 C.Com., no por el mero hecho de que ejerzan un control, sino porque a través de éste se presume que constituyen un grupo del cual son dominante, vid., MARINA (1992) p. 403.

64 Vid., Galgano (1995) p. 63.
} 
control debe recaer o ejercerse a través de aquel órgano de la sociedad que reúna entre sus facultades aquellas que permitan a la dominante dirigir la actividad de la dominada.

\section{A) El CONTROL COMO CONCEPTO UNITARIO}

Como afirmamos en la parte introductoria de este apartado, el control es respecto del grupo sólo un presupuesto para su formación. Ya que para poder hablar de grupo de sociedades es necesaria la presencia de una dirección económica unificada, siendo el control el poder de determinar la gestión de otro, y considerando, que el grupo está formado por sociedades que conservan su independencia jurídica, establecemos como primera premisa; que el dominio debe recaer sobre el órgano societario que detenta el poder de gestión, el poder de dirigir la marcha económica de la empresa, aun cuando en determinados casos, pueda afirmarse que es necesario primero tener presencia significativa en otros órganos sociales. ${ }^{65}$

Como se deduce de su texto, el artículo 42.1 del C.Com., no establece un concepto de control, sino que se limita a enumerar supuestos de hecho, en los cuales parece considerar existente una relación de dominio ${ }^{66}$ con suficiente entidad como para hacer presumible la existencia de un grupo de sociedades. ${ }^{67} \mathrm{~A}$ pesar de ello, dicho precepto ha adquirido dentro de la legislación española un cierto protagonismo en lo que a control y a grupos se refiere $^{68}$, compartido, en menor medida, con el artículo 4 LMV, tal y como hemos referenciado en apartados anteriores. Aunque el primero de ambos se limita a indicar cuándo una sociedad mercantil debe consolidar sus cuentas con las de sus dependientes. ${ }^{69}$ Motivos por los cuales, podemos considerar

65 Esta afirmación está en relación con la ya antigua discusión doctrinal sobre la posibilidad de una noción de control externo, de un "control" no basado en un vínculo financiero, posesión de una participación significativa.

66 El art. 42 del C.Com., de manera indirecta deja entrever que considera los supuestos enumerados en su punto 1 como de control, al hacer referencia en su punto 2 a la sociedad dominante.

${ }^{67}$ Desde nuestro punto de vista el artículo de referencia contempla un sistema doble de presunción, presume que en los supuestos que enumera, existe una situación de dominio y sobre esta hipótesis presume la existencia de grupo. Esta es la razón por la cual impone el deber de consolidar las cuentas anuales según la técnica de la integración global, que normalmente se utiliza en el caso de estructuras de grupo.

68 Vid., EMBID (1996) p. 1231.

69 Son muchos los autores que mantienen esta afirmación, entre otros; MARINA (1992) p. 378, Martínez-Gijón (1999) p. 25, Embid (1996) p. 1237, SÁnChez (2000) p. 23, Duque (1989) pp. 
que, a tenor de la legislación española, la consideración del concepto de domino, o lo que es lo mismo, para poder entender lo que se considera como dominio $^{70}$ debe partirse siempre del "archi" mencionado artículo 42 C.Com.

Si es evidente la quiebra del principio democrático de correspondencia entre capital y poder en el interior de la sociedad, y por lo que se refiere a facultades, la Junta General ha perdido la dirección de los destinos de la empresa social, ¿por qué el legislador sigue presumiendo la existencia de control, e incluso de grupo, cuando se es socio y se posee la mayoría de votos en la Junta General? Esta cuestión nos obliga a plantearnos, a fin de mantener la validez de nuestra postura en el sistema español, el poder que la Junta General o, deberíamos decir, los accionistas de control, poseen sobre el órgano de administración.

\section{B) El concepto de control en el artículo 42 del Código de Comercio}

El legislador del Código de Comercio no ha sido ajeno a la influencia que ejerce la Junta General sobre el órgano administrativo, y al dominio de ésta por parte de los accionistas de control. Por eso cuando en su artículo 42 apartados 1.a) y c) ${ }^{71}$ considera como un supuesto de control la posesión de la mayoría de los derechos de voto, no está considerando el dominio de la Junta General y las funciones que sobre la marcha de la empresa conserva ésta. Se contempla la posesión de la mayoría de votos, porque ésta sigue siendo, según las facultades y reglas de funcionamiento de la Junta General, la forma básica de acceder al órgano administrativo. Esto se ve corroborado con el supuesto descrito en el apartado 1.d) del mismo artículo, ya que si lo que interesa para obtener el control fuera la calidad de socio o el dominio de la Junta General, no se consideraría suficiente haber nombrado a dicho órgano sin tener en cuenta el porcentaje de votos que se necesitó para ello.

514-515. No obstante, son muchas las normas que, para el concepto de grupo o control, remiten al propio art. 42 del C.Com., entre las cuales podemos encontrar, el propio art. 4 LMV, el art. 18 LSC, al art. 20 de la Ley de Ordenación y Supervisión de los Seguros Privados, entre otras.

70 Teniendo en cuenta siempre los supuestos que se recogen en el propio art. 42 C.Com., vid., Ramírez (2001) p. 651.

71 Como podemos ver en este apartado el ejercicio del control se contempla por una pluralidad de personas o, bajo el predominio a su vez de una de ellas, a tales efectos, vid.; Ruiz (1995) p. 3337. No obstante, un sector minoritario de la doctrina considera incompatible la noción de control con su ejercicio por parte de una pluralidad de sujetos. MARTínezGıJón (1999) pp. 213-215; aunque al parecer la realidad viene demostrando lo contrario. 
Lo que contienen los apartados a), c) y d) del artículo 42 del C. xCom. son las posibilidades de derecho ${ }^{72}$ y de hecho ${ }^{73}$ de nombramiento del órgano administrativo. Por esto, por el propio concepto de control y porque el supuesto restante contemplado en el apartado $b)^{74}$ no ofrece duda de referirse al nombramiento del órgano de administración, creemos que los supuestos de control contemplados por este artículo se reducen a uno solo: presencia o influencia sobre el órgano administrativo. Además, si consideramos el control como el poder de influir o dirigir la gestión de otra persona jurídica a través del órgano de administración de la misma, debemos admitir en consecuencia que sólo en el supuesto del inciso d) del artículo 42.1 del C.Com. y, en los demás que como él contemplen algún tipo de vínculo, relación o actividad sobre el órgano administrativo ${ }^{75}$, existe una situación de control. De esta forma, en los demás casos podemos hablar de presupuestos o situaciones en las cuales el legislador presume su existencia. ${ }^{76}$

72 En este sentido, MarTínez-Gı́ón (1999) p. 213, refiere que la posesión de la mayoría de los derechos de voto se califica como control de derecho, porque se ejerce el control por derecho propio, es decir, como consecuencia directa de su participación en el capital, sin necesidad de pactos ni vínculos indirectos de control.

73 El apartado d) del art. 42.1 del C.Com., regula un caso de control de hecho, en cuanto lo que se regula es la posibilidad de que, aunque no se posea la mayoría de los derechos de voto, se nombre a los administradores, debido al absentismo a las Juntas Generales, a las limitaciones estatutarias a la asistencia a las mismas, entre otros. Este apartado contiene una referencia implícita al "control minoritario" ya mencionado. Autores como Ruíz PerIS manifiestan que lo que se produce, debido a la pulverización del capital, al absentismo de los accionistas y a las propias normas societaria de computo de mayorías es una situación de carácter oligárquico, Ruiz (1995) p. 3334 y GalGano (1988) p. 27.

74 Si bien en la doctrina existe discusión sobre la validez del supuesto contenido en este apartado. Un sector considera que el mismo obedece a una deficiente transposición de la Directiva sobre cuentas consolidadas, la cual contemplaba una figura no permitida en el ordenamiento español: la reserva estatutaria a favor de algunos socios, de las facultades de nombramiento del órgano administrativo. Por lo cual, este supuesto carece de validez en la práctica, vid.; MARTíneZ-GIJÓN (1999) p. 215. Sin embargo, otra parte de la doctrina considera aplicable esta práctica estatutaria en el ordenamiento español e incluso predica su utilidad en el caso de filiales comunes, vid. Ruíz (1995) p. 3337.

75 Puede tratarse también de una omisión, como es el no separar a los administradores de la gestión anterior, pudiendo hacerlo, como sostiene Ruíz (1995) p. 3333. Esta actitud puede entenderse como indicio de una comunidad de intereses con éstos.

76 Coincidimos con Ruiz (1995) p. 3332, quien señala que "hasta que no se dé la sustitución de los miembros del órgano administrativo, no se podrá hablar en puridad del establecimiento de una situación de control, no podrá considerarse que la sociedad se encuentre controlada". 
Por otro lado, los apartados del artículo 42.1 C. de Com., contienen mecanismos de adquisición de control que sólo se refieren al de tipo interno ${ }^{77}$ extracontractual. Además de estos, existen otras técnicas para establecer un dominio -o una coordinación- del órgano administrativo, como la comunidad de consejeros, regulada en el artículo 4 de la LMV.

Los grupos contractuales de sociedades no están regulados en el ordenamiento español, por lo cual todos los supuestos de control que recoge, lo son de control por influencia de hecho sobre el órgano administrativo. De allí, que al ser éste un órgano formalmente autónomo, adquieran importancia las facultades de nombramiento y revocación del mismo. Pero en el caso de los grupos contractuales la independencia de este órgano viene limitada por el contrato de dominación que regula la organización del grupo de sociedades. En éstos, la actuación del órgano administrativo conforme a las directrices de la sociedad dominante, viene impuesta como un deber derivado del contenido del contrato de empresa. ${ }^{78}$ Aunque para la firma de estos contratos se requiera de la aprobación de la Junta General, y por tanto tener mayoría en la misma, ello no es óbice para continuar afirmando que el control que se obtiene o que se ejerce a partir de entonces, viene causado directamente por el contenido del contrato.

Para establecer el control sobre una sociedad, no hace falta ser socio de la misma, sino que también se puede hablar de un control indirecto. Una sociedad puede controlar a otra a través del control que ejerce sobre la misma una de sus dependientes, o a través de la suma de las participaciones que posean varias de éstas. Para hablar de control indirecto solo es necesario que la titularidad del control, independientemente del tipo de que se trate -interno ${ }^{79}$,

77 Para hablar de control interno es requisito sine qua non la posesión de participaciones en el capital de la sociedad dominada, independientemente de que las mismas puedan ser insuficientes para adquirir el control necesitándose de pactos con otros socios o de los votos por acciones no poseídas en propiedad.

78 Al respecto, ESTABAN y GIRÓN (1982) p. 232, refiriéndose al derecho alemán, expresan que en el caso de los grupos contractuales de sociedades existe una importante excepción al principio de actuación con independencia del órgano administrativo, ya que entonces el Vorstand viene obligado por el contrato de dominación a seguir las instrucciones de la sociedad dominante. En estos grupos se reconoce formalmente el derecho de instrucción de la sociedad dominante. También, Ruíz (1995) p. 3343-3348, entiende que, junto con los contratos de dominación, son también medios para adquirir un control externo contractual, la franquicia, la concesión, la agencia, e incluso habla de la posibilidad de establecer un control por medio de contratos de financiación. Vid., Ruíz (1995) p. 3341. 
externo: contractual o extracontractual ${ }^{80}{ }_{-}$, sea ejercido por la dependiente o dependientes de la indirectamente dominante, pudiendo darse el caso de que entre ésta y la indirectamente dominada no exista relación alguna.

\section{EL CONTROL SOCIETARIO COMO PRESUPUESTO DEL GRUPO DE SO- CIEDADES}

\section{Características del control}

Al hablar de control, la doctrina indica que este poder deberá tener como características la estabilidad y la generalidad. ${ }^{81}$ El dominio debe de ser general -al menos potencialmente- ya que la gestión sobre la que se ejerce está formada por una diversidad de actos y a la vez constituye un proceso unitario.

Por otro lado, si consideramos que el control es uno de los presupuestos para la formación de un grupo, será necesario que se trate de una posibilidad estable de dirigir la gestión ajena, para que sobre el mismo pueda establecerse una dirección unitaria. En este sentido, si bien una relación de control no equivale necesariamente a un grupo de sociedades, debe de ser potencialmente apta para que sobre la misma se configure la dirección unificada ${ }^{82}$, en el caso de los grupos por subordinación.

\section{Situación de control y concepto de grupo de sociedades}

$\mathrm{Al}$ ser el control un poder, no es necesario para su existencia que se produzca su ejercicio, sino sólo que éste sea posible. En este matiz creemos que se encuentra la diferencia entre control e influencia dominante. Así pues, el control existe desde el momento en que se posee la capacidad de ejercer una influencia dominante sobre otra sociedad. ${ }^{83}$ La influencia dominante se pue-

$80 \quad$ Ídem., p. 3316.

81 Vid., Antunes (1993) pp. 359-380, Ruiz (1995) p. 3329.

82 Al respecto, MARTíneZ-Gı́ón (1999) pp. 210-211, el cual defiende que el control es un presupuesto para el ejercicio de la influencia dominante y de la dirección unitaria. Así como, SÁNCHEZ (2000) p. 19, que reconoce que en el grupo de sociedades han de manifestarse conjuntamente los dos elementos: la dominación o control sobre una o varias sociedades y su sometimiento a una dirección única.

83 La doctrina manifiesta que el control es un presupuesto para el ejercicio de una influencia dominante, siendo a la vez inseparables ésta y el control. De tal manera que sólo se puede decir que una sociedad controla a otra cuando tiene la capacidad necesaria para ejercer una influencia dominante sobre ella. El autor se refiere en este sentido a un control efectivo, MARTínez-GıJón (1999) p. 210. 
de entender como el conjunto de posibilidades de actuación que se obtienen al adquirir el control y como el ejercicio concreto y puntual de ese conjunto de posibilidades -todas o algunas-. De esta forma, mientras el control puede ser meramente potencial, cuando -en el ordenamiento español- se hace referencia a la existencia de una situación de influencia dominante, se está hablando necesariamente de un ejercicio de ese conjunto de posibilidades ligadas al control. ${ }^{84}$ Por tanto, el control puede ser potencial o actual y en el caso de que fuese actual estamos hablando del ejercicio o de una situación de influencia dominante.

Como bien hemos planteado en epígrafes anteriores, el elemento que define la existencia de un grupo de sociedades es la dirección unitaria. Aunque en algunas ocasiones el legislador defina al grupo de sociedades en función de la existencia de dirección unitaria, no es usual la determinación del contenido de la misma, sino que generalmente se recurre a la técnica de presumir su presencia en los casos de control o dependencia. Al respecto, hemos de indicar que cuando el ejercicio del control es planificado y estable, y no referido solamente a un aspecto en concreto ni a un momento puntual, estaremos frente a una dirección unitaria ${ }^{85} \mathrm{y}$, por tanto, frente a un grupo de sociedades. La dirección unitaria es una actividad de gobierno continuada. ${ }^{86}$ Hablar de dirección unitaria -y con ella del establecimiento de una unidad económica- implica traspasar las fronteras de una simple situación de control o de influencia dominante, pasando del ámbito societario a una nueva forma de empresa: el grupo. ${ }^{87}$

En el grupo de sociedades por subordinación se construye una organización jerárquica, en virtud de la cual y mediante el poder de dirección, se imparten instrucciones a los órganos de gestión de las sociedades dependientes. La extensión de la dirección unitaria determina la estructura de los grupos de sociedades, de modo que cuando la misma se ejerce solo sobre los asuntos de financiación y personal ${ }^{88}$ estaremos frente a un grupo descentralizado,

${ }^{84}$ Vid., EMBID (1996) p. 1230.

85 El poder de dirección se concreta no en un hecho que se produce en un determinado momento, como puede ser la designación de administradores, sino en algo permanente, vid., SÁNCHEZ (2000) p. 20.

86 Vid., ídem., p. 21.

87 Vid., EMBID (1996) p. 1230.

88 Teniendo en cuenta el contenido de la dirección unitaria, vid., EMBID (1989) p. 386, expresando entre otras cuestiones que la dirección unitaria para ser tal debe recaer como mínimo sobre las materias de financiación y personal; la competencia para decidir sobre estas materias constituye el contenido mínimo de ésta. 
y cuando se extienda a otros sectores de la actividad económica de las dominadas ventas, producción, entre otras; el grupo será de tipo centralizado. En estos últimos, el interés de la empresa del grupo debe prevalecer incondicionalmente en todos los casos y la autonomía jurídica de las sociedades dependientes es una pura formalidad, de forma que -a través de la dirección unitaria- se convierte a las sociedades integrantes, en simples departamentos dentro de la gran empresa del grupo de sociedades. En los grupos descentralizados, en cambio, las sociedades dependientes suelen conservar una parcela -de contenido variable- de comportamiento empresarial autónomo. ${ }^{89}$

\section{EL INTERÉS DEL GRUPO DE SOCIEDADES}

\section{Legitimación del interés del grupo de sociedades}

Si partimos de que el fenómeno del grupo de sociedades surge cuando varias sociedades se unen y actúan bajo una dirección común, es lógico pensar que dicha dirección debe tener un propósito, que no puede ser otro que la consecución de un objetivo económico, con la peculiaridad de que, para la consecución de ese fin, cada una de las sociedades constituye una mera parte del todo; es decir, la empresa pasa de situarse en el plano societario al plano plurisocietario, de manera que la empresa ya no la constituye una sociedad individualmente considerada, sino que la empresa es el grupo. ${ }^{90}$ Ese perseguido objetivo económico, a cuya consecución la dirección unitaria va a aspirar, se denomina interés del grupo ${ }^{91}$ y se manifiesta en la búsqueda del máximo beneficio conjunto, aunque no necesariamente para todos los miembros.

Como bien nos hemos referido anteriormente, el propio concepto de grupo de sociedades se encuentra ya recogido en algunas normas sectoriales del ordenamiento español; el legislador no desconoce el fenómeno del grupo, sino que lo reconoce. He aquí donde nos encontramos con la paradoja; de la diversidad de normas que hacen alusión al grupo de sociedades parece desprenderse que el grupo se encuentra, de alguna manera, legitimado; sin

$89 \quad$ Vid., ídem., pp. 366 y 367.

90 En este sentido, GiRón (1986) p. 202, se refiere al grupo con el término "superempresa".

91 El concepto de interés de grupo no resulta extraño en la literatura jurídica española, muchos son los autores que se han preocupado por estudiar el alcance, significado y legitimidad del mismo, y es que, en efecto, el problema nace de la circunstancia de que el Derecho de sociedades español está configurado para que sea una sola persona jurídica la que desarrolle una actividad económica y, por lo tanto, todo el régimen jurídico para su funcionamiento queda articulado en torno a esta previsión. Es precisamente aquí donde el derecho colisiona con la realidad. 
embargo, el legislador no le ha otorgado los instrumentos necesarios para su correcto desarrollo.

A diferencia de lo que ocurre en el Derecho español, en Brasil existe una regulación específica sobre los grupos de sociedades de tipo contractual recogida en los artículos 265 a 277 LSAB. Esta regulación obliga a los administradores de las sociedades filiales a observar las instrucciones de los administradores del grupo que no supongan violación de la ley o del contrato de grupo, artículo 273 LSAB. Por otro lado, en el ordenamiento brasileño también encontramos grupos de facto, que son aquellos que no se han constituido de conformidad a lo establecido en las normas citadas, por lo que se regularán según lo previsto para las situaciones de control accionarial, artículos 116 a 118 LSAB y en las normas del Código Civil brasileño, artículos 1097 a 1101, específicamente el artículo 1098, que trata las sociedades controladas.

El problema del grupo en el Derecho español se concreta en la dificultad de poder legitimar la actuación del conjunto de las sociedades que lo forman en orden a la consecución del interés común o interés del grupo, máxime cuando alguna de estas pudiera resultar perjudicada a consecuencia de una instrucción perjudicial, produciéndose conflicto de intereses en su seno: el del grupo de sociedades como empresa plurisocietaria y el de la sociedad individual. Es por ello que la verdadera problemática del fenómeno no subyace tanto en declarar legítimo, o no, el ejercicio de ese poder de dirección externo a la sociedad, como en admitir que tal poder se dirija a la consecución de un interés distinto -el interés del grupo- que, en algunas ocasiones, será contrario al interés individual de las sociedades agrupadas. ${ }^{92}$

\section{La legitimidad del grupo y del ejercicio de la dirección unitaria o externa}

Actualmente, son cada vez menos frecuentes, y ya no son sólo objeto de crítica unánime por parte de nuestra doctrina científica, también buena parte de la jurisprudencia viene manifestándose en los últimos años en un sentido contrario a concebir cualquier poder de dirección externa en una suerte de

92 En este sentido, Fuentes (2007) p. 134, sitúa en este ámbito (la actuación en interés distinto) el problema del grupo de sociedades, pues considera que la existencia de un poder de dirección externo no es obstáculo en el ordenamiento español, en el que se reconoce la posibilidad de llevar a cabo un poder de dirección proveniente de instancias diferentes al órgano de administración de la sociedad, por ejemplo: la posibilidad de que la Junta pueda impartir instrucciones vinculantes o el reconocimiento que el legislador hace en el artículo 78 de la Ley de Cooperativas de que existen sociedades dominantes que pueden ejercer su influencia sobre otras. 
fraude de ley, que justifique el desconocimiento de las personalidades jurídicas diferenciadas del sujeto que ejerce el poder y del sujeto que queda sometido a él.

En la actualidad, queda fuera de toda duda que el grupo es una estructura legítima y reconocida por el legislador español, y ello a pesar de que las referencias de las leyes españolas al grupo son escasas y en ocasiones dispares, lo que dificulta deducir con nitidez los criterios de política jurídica que existen en nuestro ordenamiento respecto de esta figura. Tal reconocimiento se desprende claramente de las múltiples referencias que en él se hace al grupo, lo que, unido al principio constitucional de la libertad de empresa, refleja un propósito tal vez inconsciente pero único: el reconocimiento del grupo como institución legítima y plenamente concorde con nuestro ordenamiento. ${ }^{93}$

La problemática acerca de la legitimidad del grupo ya no se sitúa en torno a la legitimidad o no del ejercicio de una dirección externa sobre las sociedades que lo forman, sino en determinar si la consecución del interés global de la empresa de grupo en detrimento del interés particular de esas sociedades puede considerarse también legítima.

\section{Las instrucciones perjudiciales como medio de alcanzar interés del grupo}

Será perjudicial aquella instrucción que impartida por la matriz provoque una disminución efectiva o un peligro real para el patrimonio de la sociedad filial afectada, siempre y cuando se emita en interés del grupo. En sentido amplio, ha de entenderse por instrucción cualquier medida adoptada por la sociedad matriz mediante la cual quiere influir e influye en la gestión de la sociedad filial, incluyendo no solo las instrucciones en sentido estricto -órdenes-, sino también cualquier otro tipo de declaración de voluntad de la matriz -consejos, directivas, recomendaciones, etc.- en virtud de las cuales la sociedad filial se vea obligada a modificar su comportamiento adecuándolo a las directrices de la matriz ${ }^{94}$. Una instrucción perjudicial es aquella que obliga a tomar una serie de medidas que un administrador de una sociedad, independiente, que actuara diligentemente en interés de su sociedad no adoptaría. Estas instrucciones se materializarán habitualmente en la celebración de negocios jurídicos o en la adopción de determinadas medidas o actos por la sociedad filial -ya se trate de un comportamiento activo o pasivo- ${ }^{95}$

\footnotetext{
$93 \quad$ Vid., EMBID (2003) p. 31.

94 Vid., De ArRiBA (2009) p. 247.

$95 \quad$ Ídem., pp. 403 y 404.
} 
En determinadas ocasiones, la realidad del tráfico impone que sea necesario llevar a cabo un acto perjudicial para una de las sociedades del grupo, si este acto, trae como resultado un beneficio mayor para el conjunto de la empresa plurisocietaria. Se plantea entonces la cuestión, de si al amparo del interés del grupo, es legítimo que la dirección unitaria del grupo imparta instrucciones que se traduzcan en actos perjudiciales para alguna de las sociedades integrantes. La cuestión no es sencilla, si se tiene en cuenta que, las instrucciones perjudiciales plantean un problema de conflicto de intereses al colisionar con el deber de fidelidad de los administradores de la sociedad que las reciben.

Ante la problemática del conflicto de intereses, y a falta de un régimen jurídico ad hoc que lo resuelva, la mayoría de la doctrina ha concluido que la legitimidad del grupo de sociedades se dará en tanto no vulnere el ordenamiento societario vigente. ${ }^{96}$ La consecución del interés del grupo no puede perjudicar el interés particular de ninguno de sus miembros, por lo que sus efectos deberán ser positivos o, cuando menos, neutros para el interés particular de cada una de las sociedades integradas en él. Por más que se apele al interés del grupo, no resulta justificado que en el derecho español se pueda perjudicar a una sociedad sin una efectiva compensación.

\section{La valoración del perjuicio en el grupo de sociedades: la doctrina de las ventajas compensatorias}

Cabe plantearse, si de la propia existencia del grupo y la complejidad de las relaciones que se establecen de manera habitual entre sus miembros, como resultado de la dirección unitaria en interés del grupo, debe resultar en un examen del concepto del perjuicio de los actos intragrupo bajo unos parámetros idénticos que, si de una "sociedad isla" se tratase, o si, por el contrario, se debe examinar la operación desde una perspectiva diferente.

Los ordenamientos que se han ocupado de regular el fenómeno de los grupos de sociedades, han reconocido la existencia de un interés de grupo y han tratado salvaguardarlo articulando mecanismos que permitan su consecución, a la vez que se protegen intereses de terceros. ${ }^{97}$ Para ello, se ha recurrido a la llamada doctrina de las ventajas compensatorias que legitima

96 Vid., Embid (2003) p. 32, Girgado (2001) p. 277, Sánchez-Calero (2005) pp. 7-70, Fuentes (2007) p. 146-151.

97 En el derecho comparado, la doctrina de las ventajas compensatorias tuvo su origen y posterior desarrollo en la labor de la jurisprudencia. En el caso de Italia, esa doctrina fue llevada a los textos legales en el 2003. También se encuentra presente en el ordenamien- 
la injerencia de un perjuicio a una sociedad integrada en un grupo, siempre que de la operación se derive un beneficio para el conjunto, y la sociedad perjudicada sea efectivamente compensada por la desventaja sufrida, por lo que se debe hacer un balance entre los sacrificios y ventajas que la pertenencia al grupo supone para esa sociedad. Aunque en aplicación de la doctrina de las ventajas compensatorias, el juicio sobre la legitimidad de la dirección unitaria sigue dependiendo de que el interés de la sociedad filial no se vea perjudicado, lo determinante es la incorporación de una valoración distinta sobre el respeto a tal interés, teniendo en cuenta no a la sociedad del grupo aisladamente, sino, al conjunto de relaciones en que se halla involucrada.

Para que la doctrina resulte aplicable habrían de cumplirse determinados requisitos: (i) ha de tratarse de una operación resultado de una política de grupo y realizada en interés del grupo, (ii) debe de preverse una compensación adecuada, y (iii) el acto perjudicial debe respetar la supervivencia de la sociedad, es decir, esa instrucción o acto no podrá ser determinante de que la sociedad quede en estado de insolvencia. ${ }^{98}$

Aunque la doctrina de las ventajas compensatorias no es desconocida en nuestro derecho proyectado, pues su aplicación ya fue planteada e incluida en el borrador del proyecto del Código de Sociedades Mercantiles, se plantea si esta teoría es aplicable en nuestro ordenamiento sin necesidad de una reforma legislativa. La aplicabilidad de esta teoría en nuestro Derecho de sociedades podría contar principalmente con dos obstáculos; (i) la prohibición de la compensatio lucri cum damno, artículo 1686 Código Civil español (en adelante CC) y (ii) el deber de fidelidad del administrador. Sin embargo, quien se ha ocupado de estudiar la cuestión no ha encontrado óbice a que ésta se aplique lege lata en el ordenamiento español.

Por lo que respecta a la primera cuestión, ha de entenderse que la desventaja no es un daño o un perjuicio, sino un valor de contraprestación. De este modo, sólo cuando la desventaja no sea compensada en tiempo y forma oportuna, se considerará que se ha ocasionado un daño, y, el deber jurídico de compensación se transformará en una obligación de indemnizar por los perjuicios causados. El otro gran obstáculo, el deber fidelidad, que recae sobre el administrador de la sociedad filial que ha de acatar la instrucción perjudicial, quedaría salvado al reinterpretar el principio de interés social de un modo más amplio, considerando que tal interés debe de ser concebido

to alemán, aunque el principio se materializa de forma diferente en función del tipo de grupo que se trate (contractual, fáctico o por incorporación). 
como un interés consciente de su necesaria coordinación con un interés global de la empresa que constituye el grupo. Así, la contradicción que supone el enfrentamiento del interés social que cada sociedad del grupo persigue y los sacrificios que le son exigidos en nombre del interés común, es superada a través de la disociación temporal de la noción de interés social, puesto que si la sociedad comete un acto contrario a su interés social inmediato a favor del interés del grupo, está en realidad persiguiendo su interés social propio, en la medida en que puede razonablemente atender una contrapartida futura por este sacrificio. ${ }^{99}$

Aun habiendo sido identificada la teoría de las ventajas compensatorias como la solución idónea al conflicto de intereses intragrupo, no existe en la doctrina, jurisprudencia y legislación comparada, consenso en torno a lo que se debe considerar una adecuada compensación. En términos generales, distinguimos dos corrientes: (i) la teoría cuantitativa, y (ii) la teoría cualitativa, caracterizada por una mayor flexibilidad. ${ }^{100}$

La posición cuantitativa, paradigmática del ordenamiento alemán, requiere que el otorgamiento de la ventaja deje a la sociedad como si nunca hubiese sufrido desventaja alguna, lo que exige que el perjuicio se compense por completo, y si no, de forma simultánea, pero sí muy cercana en el tiempo. Esta posición ha sido objeto de críticas, al entenderse que exigir una rígida identificación cuantitativa entre ventaja y desventaja significa desconocer la realidad del grupo, pues subordinar la legitimidad de la consecución del interés del grupo a la obtención de un resultado económico, equivalente al que se habría obtenido de haber sido la sociedad independiente, refleja la idea tradicional de que el interés del grupo se justifica en tanto haya una ausencia de perjuicio para la filial.

La postura que defiende una compensación cualitativa parte de una concepción en la que prima el funcionamiento del grupo como empresa, en la que cada sociedad en él integrada, es una pieza más destinada a favorecer la riqueza del conjunto, propugnándose una teoría de la compensación que se basa en un procedimiento valorativo asentado en la racionalidad, coherencia y eficiencia del acto -aun cuando sea perjudicial para la sociedad- respecto de una mejoría económica general de grupo a medio y largo plazo, de la cual razonablemente, puede derivar una ventaja para la sociedad en cuestión, aun cuando sea sobre planos económicos o momentos distintos respecto de aquel

\footnotetext{
99 De esta problemática se ha ocupado en profundidad ídem., pp. 153-155, quien también ha citado doctrina extranjera.

100 Ídem., pp. 155-194.
} 
en que tuvo lugar la operación, y también, según un parámetro no rígidamente proporcional ni necesariamente cuantitativo. ${ }^{101} \mathrm{El}$ referente legislativo de esta posición es el ordenamiento italiano, si bien con mayor claridad en el ámbito penal que en el civil.

Ahora bien, los defensores de la aplicabilidad de la doctrina de las ventajas compensatorias basada en una valoración cualitativa de la compensación, no por ello deja de considerar que aquella compensación, aunque no sea cuantitativa, sí debe ser proporcional, ya que únicamente la relación proporcional entre ventajas y desventajas convertirá la compensación en adecuada y justificará la adopción por parte de la sociedad de grupo de medidas desventajosas para su propio interés. La compensación también debe ser cierta, es decir, que no sea hipotética o virtual. ${ }^{102}$

\section{CONCLUSIONES}

La LSAB establece claramente una distinción entre las fases de adquisición de control y la de constitución del grupo, éste último perfeccionándose mediante el contrato de convención, de ahí el carácter dinámico de dicha normativa. No obstante, la misma carece de una mención expresa de la dirección unitaria, así como de disposiciones normativas en materia de responsabilidad. Carece, a su vez, de una regulación de los grupos fácticos, pudiendo ampliar la regulación de las técnicas de adquisición del control, sobre todo de las societarias.

La regulación legal española puede ser calificada como insuficiente o de intervención mínima, debido a que solamente se regulan algunos aspectos puntuales, concretos o incidentales del orden mercantil, laboral, fiscal, contable, procesal, entre otros, de los grupos de sociedades, en función de los intereses o bienes jurídicos que cada rama o, mejor dicho, que cada norma del Derecho desea proteger y de las necesidades que puedan ir surgiendo.

La ausencia de una adecuada normativa societaria respecto al grupo, en el ordenamiento jurídico español, así como la dispersión de su tratamiento en otros sectores jurídicos, no debe suponer un obstáculo para sentar las bases de un necesario Derecho de grupos. Sin olvidar la complejidad del supuesto de hecho objeto de regulación, en el que confluyen una gran variedad de

101 Vid., Fuentes (2007) p. 195.

102 Fuentes (2007) pp. 173 y 174, defiende la aplicabilidad, en el ordenamiento español, de una postura en la que la compensación sea cualitativa, proporcional y cierta, al respecto. 
aspectos sustanciales, como son; interés de las partes, organización del grupo, relaciones internas de las sociedades integrantes del grupo y la legitimidad.

El sistema de regulación de los grupos de sociedades en el ordenamiento español tiende a ser tuitivo, pero no en razón de los aislados conceptos que otorga cada rama del ordenamiento jurídico. Los cuales, definen al grupo solo en función de la vinculación entre las sociedades que lo conforman, sino de los aislados preceptos que regulan supuestos específicos sobre los grupos de sociedades, en los que generalmente se busca la protección de los bienes jurídicos de cada rama del Derecho a la que pertenecen y en donde la noción de grupo se considera como predefinida.

En materia de Derecho comunitario, consideramos necesario una regulación conjunta armonizadora de todos los países miembros. Ya que la dimensión del grupo, en un mundo globalizado y en el que las relaciones comerciales cada vez son más internacionalizadas, los grupos de sociedades juegan un papel fundamental en las mismas. Motivos por los cuales, la dimensión del grupo, cada vez más, rebasa las fronteras nacionales de los Estados, lo que puede ocasionar grandes problemas de aplicación normativa, así como cuestiones de extraterritorialidad de las normas.

\section{BIBLIOGRAFÍA CITADA}

ANTUNES, José Engrácia (1993): Os grupos de sociedades (Coímbra, Editorial Almedina).

(1995): "The law of affiliated companies in Portugal", en AA.VV.: I Gruppi di Societá, Venezia: Atti del convengo internazionale di studi, 16-17-18 novembre 1995 (Milano, A. Giuffrè Editore) pp. 355-388.

Boldó, Carmen (2006): Levantamiento del velo y persona jurídica en el Derecho privado español (Navarra, Editorial Aranzadi S.A).

De Arriba, María (2009): Derecho de grupos de sociedades (Navarra, Editorial Aranzadi).

Duque Domínguez, Justino F. (1989): "El derecho de las empresas vinculadas en la legislación española (especialmente en la Ley de reforma parcial y de adaptación a las Directivas comunitarias en materia de sociedades y en la Ley del Mercado de Valores)", Revista de Derecho Bancario y Bursátil, vol. 9 n 35: pp. 465-526. 
(1996): "Los métodos de grupos de sociedades", ponencia en VII Congreso Internacional de Derecho Comparado, Barcelona: Instituto de Derecho Comparado.

Embid IRUjo, José Miguel (1989): “Los grupos de sociedades en la Comunidad Económica Europea (El proyecto de Novena Directiva)", CDC, $\mathrm{n}^{\circ}$ 5: pp. 359-417.

(1996): "La problemática de los grupos", en AA.VV.: II Derecho de sociedades de responsabilidad limitada. Estudio sistemático de la Ley 2/1995 (Madrid, Editorial Mc Graw-Hill) pp. 1223-1242.

(2003): Introducción al derecho de los grupos de sociedades (Granada, Editorial Comares).

(2010): Ley alemana de sociedades anónima (Madrid, Editorial Marcial Pons).

Embid Irujo, José Miguel y Salas Fumás, Vicente (2005): El gobierno de los grupos de sociedades (Madrid, Fundación Alternativas, Documento de trabajo $\left.n^{\circ} 64\right)$.

EstabAn, Gaudencio y Girón, José (1982): El poder de decisión en las sociedades anónimas. Derecho Europeo y reforma del Derecho español (Madrid, Editorial Civitas).

Fernández Markaida, Idoia (2001): Los grupos de sociedades como forma de organización empresarial (Madrid, Editorial de Derecho Reunidas S.A).

Fernández Ruiz, José Luis (1995): "Algunas acotaciones sobre el concepto de grupos de sociedades en los derechos mercantil y laboral", en AA.VV., Estudios de Derecho Mercantil en homenaje al profesor Manuel Broseta Pont (Valencia, Editorial Tirant lo Blanch) pp. 1219-1238.

Fuentes, Mónica (2007): Grupo de sociedades y protección de acreedores. Una perspectiva societaria (Madrid, Editorial Thomson-Civitas).

Galgano, Francesco (1988): La societá per azioni (2ª edición, Padova, Editorial Padova).

(1995): "El desplazamiento del poder en las sociedades anónimas europeas", en AA.VV.: Estudios Jurídicos sobre la Sociedad Anónima (Madrid, Editorial Civitas) pp. 63-86. 
Girón, José (1986): Tendencias actuales y reforma del Derecho mercantil (Madrid, Editorial Civitas).

Girgado, Pablo (2001): La empresa de grupo y el Derecho de sociedades (Granada, Editorial Comares).

LÓPEZ EXPÓSITO, Antonio Jesús (2014): "Los grupos de sociedades, ¿ámbitos ajenos a la responsabilidad ante acreedores y socios", eXtoikos, $\mathrm{n}^{\circ} 13$ : pp. 31-36.

López Martínez, Luis Manuel (1996): Los grupos de sociedades en el ordenamiento jurídico español y colombiano (Colombia, Editorial Temis S.A).

MARINA, Ángel (1992): Régimen jurídico de la contabilidad de empresario (Valladolid, Editorial Lex Nova).

Martínez-Gijón Machuca, Pablo (1999): "El fenómeno del control o de dependencia entre las sociedades", Revista de Derechos de Sociedades, $\mathrm{n}^{\circ} 12$ : pp. 210-229.

Paz-Ares Rodríguez, José Cándido (2014): “Uniones de Empresas y Grupos de Sociedades", en Menéndez Menéndez, Aurelio y Rojo Fernández, Ángel (dirs.), Lecciones de derecho mercantil (12 ${ }^{\mathrm{a}}$ edición, Navarra, Editorial Aranzadi) pp. 636-656.

Ramírez Otero, Lorena (2001): "El control y los grupos de sociedades", Anuario da Facultade de Direito da Universidade da Coruña, n 5: pp. 629-664.

Rojo Fernández-Río, Ángel José (1996): "Los grupos de sociedades en el Derecho Español", Revista de Derecho Mercantil, n²220: pp. 457- 484.

RuIz, Juan Ignacio (1995): "Significado del control empresarial en el derecho español", en AA.VV.: III Estudios en homenaje al profesor Manuel Broseta Pont (Valencia, Editorial Tirant lo Blanch) pp. 3315-3354.

SÁnchez Calero, Fernando (1979): "Grupos de sociedades y mercados de valores", Boletín Financiero de la Bolsa de Barcelona, no 69.

SÁnchez Calero, Francisco Javier (2000): "De nuevo sobre la regulación de los grupos de sociedades", Revista de Derecho Bancario y Bursátil, vol. 19 $\mathrm{n}^{\circ}$ 77: pp. 7-64. 
Sánchez-Calero Guilarte, Juan (2005): "Algunas cuestiones concursales relativas a los grupos de sociedades", Anuario de Derecho Concursal, $n^{\circ} 5$ : pp. 7-60.

Sebastián QuetGlas, Rafael (2009): “La insolvencia de los grupos de sociedades: una reforma pendiente", en Fernández RodríGuez, Antonio, RodríGuez, José Antonio y Sebastián, Rafael (drs.), La Ley Concursal y su aplicación (Madrid, Fundación de Estudios Financieros) pp. 93-110.

\section{NORMAS JURÍDICAS CITADAS}

Código Civil de Brasil, Ley № 10.406 de 10 de enero de 2002, entrada en vigor 11 de enero de 2003.

Código Civil de España, Real Decreto de 24 de julio de 1889. Boletín Oficial del Estado n 206, de 25 de julio de 1889, última modificación de 6 de octubre de 2015.

Código de Comercio de España

Código de Sociedades Comerciales (Portugual), Decreto-Ley $n^{\circ}$ 262/86. Diario de la República de Portugal, de 2 de septiembre de 1986.

Ley de Mercado de Valores (España), Real Decreto Legislativo n ${ }^{\circ}$ 4/2015, aprueba su texto refundido, de 23 de octubre de 2015.

Ley de Ordenación y Supervisión de los Seguros Privados (España), Real Decreto Legislativo 6/2004, aprueba su texto refundido, de 29 de octubre de 2004.

Ley de Sociedades Anónimas (Brasil), Ley n 6.404, 15 diciembre 1976.

Ley de Sociedades de Capital (España), Real Decreto Legislativo 1/2010, aprueba su texto refundido, de 2 de julio de 2010.

Ley n 16/2007 (España), de reforma y adaptación de la legislación mercantil en materia contable para su armonización internacional con base en la normativa de la Unión Europea, de 4 de julio de 2007.

Ley ${ }^{\circ}$ 43/1995 (España), del Impuesto sobre Sociedades, de 27 de diciembre de 1995. 


\section{JURISPRUDENCIA CITADA}

Audiencia Provincial Barcelona (2015): 30 junio 2015, SAP B 6634/2015, resolución n ${ }^{\circ}$ 170/15. Disponible en: <http://www.poderjudicial.es/search/ doAction?action $=$ contentpdf \& databasematch $=$ AN \& reference $=7460497$ \&links $=\% 22170 \% 2 F 2015 \% 22$ \&optimize $=20150907 \&$ publicinterface $=t$ rue>, fecha de consulta: 15 de septiembre de 2016.

Tribunal de Justicia de la Unión Europa, Eurofood IFSC Ltd. (2006): 2 mayo 2006, asunto C-341/04. Disponible en: <http://eur-lex.europa.eu/legalcontent/ES/TXT/PDF/?uri=CELEX:62004CJ0341\&rid=1>, fecha de consulta: 15 de septiembre de 2016.

Akzo Nobel NV y otros contra Comisión de las Comunidades Europeas (2009): 10 septiembre 2009, asunto C-97/08. Disponible en: <http://eurlex.europa.eu/legal-content/ES/TXT/HTML/?uri=CELEX:62008CJ0097\&r id=3>, fecha de consulta: 15 de septiembre de 2016.

Tribunal Superior de Justicia de Galicia (2015): 13 octubre 205, STSJ GAL 7859/2015, resolución no 5645/2015. Disponible en: <http://www.poderjudicial.es/search/doAction?action $=$ contentpdf \&databasematch $=\mathrm{A}$ N\&reference $=7514750 \&$ links $=\% 225645 \% 2 F 2015 \% 22$ \&optimize $=201$ 51110\&publicinterface=true $>$, fecha de consulta: 15 de septiembre de 2016.

Tribunal Superior de Justicia de Navarra (2015): 21 mayo 2015, STSJ NA 224/2015, resolución $n^{\circ}$ 219/2015. Disponible en: < http://www. poderjudicial.es/search/doAction?action=contentpdf\&databasematch= AN\&reference $=7452577$ \&links $=\% 22219 \% 2 F 2015 \% 22$ \&optimize $=201$ 50821\&publicinterface $=$ true $>$, fecha de consulta: 15 de septiembre de 2016.

Tribunal Supremo (2014): 28 febrero 2014, STS 735/2014, resolución $\mathrm{n}^{\circ}$ 80/2014. Disponible en: <http://www.poderjudicial.es/search/ documento/TS/6991100/Levantamiento\%20del\%20velo/20140314>, fecha de consulta: 15 de septiembre de 2016.

(2014): 30 abril 2014, STS 1954/2014, resolución $n^{\circ}$ 100/2014. Disponible en: < http://www.poderjudicial.es/search/doAction?action=c ontentpdf\&databasematch $=$ TS\& reference $=7084748 \&$ links $=\% 22100 \% 2$ F2014\%22\&optimize $=20140602$ \& publicinterface $=$ true $>$, fecha de consulta: 15 de septiembre de 2016. 
(2014): 17 julio 2014, STS 3166/2014, resolución $n^{\circ}$ 429/2014. Disponible en: <http://www.poderjudicial.es/search/documento/ TS/7140923/Levantamiento\%20del\%20velo/20140807>, fecha de consulta: 15 de septiembre de 2016. 